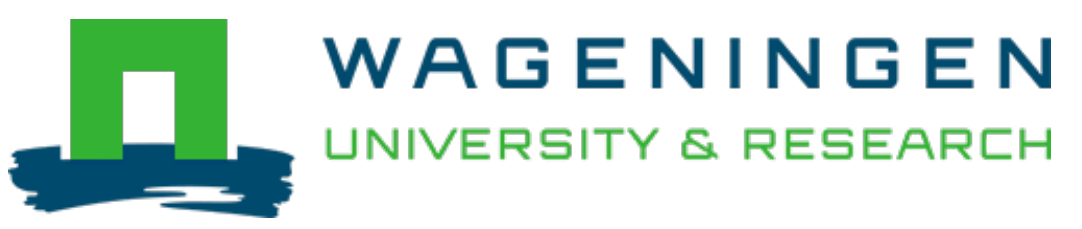

\title{
Natural variation in patterns of polysomaty among individual tomato plants and their regenerated progeny
}

\author{
Plant Science \\ Smulders, M.J.M.; Rus-Kortekaas, W.; Gilissen, L.J.W.J. \\ https://doi.org/10.1016/0168-9452(95)04082-6
}

This article is made publicly available in the institutional repository of Wageningen University and Research, under the terms of article $25 \mathrm{fa}$ of the Dutch Copyright Act, also known as the Amendment Taverne. This has been done with explicit consent by the author.

Article 25 fa states that the author of a short scientific work funded either wholly or partially by Dutch public funds is entitled to make that work publicly available for no consideration following a reasonable period of time after the work was first published, provided that clear reference is made to the source of the first publication of the work.

This publication is distributed under The Association of Universities in the Netherlands (VSNU) 'Article $25 \mathrm{fa}$ implementation' project. In this project research outputs of researchers employed by Dutch Universities that comply with the legal requirements of Article $25 \mathrm{fa}$ of the Dutch Copyright Act are distributed online and free of cost or other barriers in institutional repositories. Research outputs are distributed six months after their first online publication in the original published version and with proper attribution to the source of the original publication.

You are permitted to download and use the publication for personal purposes. All rights remain with the author(s) and / or copyright owner(s) of this work. Any use of the publication or parts of it other than authorised under article $25 \mathrm{fa}$ of the Dutch Copyright act is prohibited. Wageningen University \& Research and the author(s) of this publication shall not be held responsible or liable for any damages resulting from your (re)use of this publication.

For questions regarding the public availability of this article please contact openscience.library@,wur.nl 


\title{
Natural variation in patterns of polysomaty among individual tomato plants and their regenerated progeny
}

\author{
M.J.M. Smulders*, W. Rus-Kortekaas, L.J.W. Gilissen \\ Centre for Plant Breeding and Reproduction Research (CPRO-DLO), P.O. Box 16, NL-6700 AA Wageningen, \\ The Netherlands
}

Received 16 November 1994; revision received 26 January 1995; accepted 30 January 1995

\begin{abstract}
Using flow cytometry, the patterns of polysomaty were determined in individual organs of seedlings of tomato (Lycopersicon esculentum L. cv. Moneymaker). On average, each organ (i.e. leaf, cotyledon, transition zone from hypocotyl to primary root, and secondary root) displayed its own pattern of polysomaty. However, the percentages of nuclei at each $\mathrm{C}$-level $(1 \mathrm{C}=$ the DNA content after meiosis) varied greatly among individual plants, notably in cotyledons and transition zones. In the latter organ, the percentages of $2 \mathrm{C}$-nuclei ranged from 19 to $43 \%$. When plotted against the percentage of $2 \mathrm{C}$-nuclei, the percentages of nuclei at other $\mathrm{C}$-levels in leaf, cotyledon and transition zone fitted in a continuous pattern. In agreement with this, the polysomaty patterns of some leaves with relatively high levels of polysomaty were identical to those of the cotyledons with relatively low levels of polysomaty. The same was the case with some cotyledon and transition zone samples. These results might suggest developmental variation among the individual organs. However, the polysomaty patterns of individual cotyledons did not correlate with other parameters of development, such as the size of the organ, nor with the patterns of polysomaty in the leaf or transition zone of the same seedling. In first generation seedlings from plants regenerated from tissue culture, the extent of the variation in polysomaty had increased, especially in the cotyledons. Also, seedling populations of several regenerants displayed aberrant frequency distributions of $2 \mathrm{C}$-nuclei in the cotyledons. However, the second-generation progeny did not show any of these aberrations, and the standard deviations of the second generation cotyledons were comparable to those of the control population. It is concluded that the deviations in the pattern of polysomaty can be due to unstable, epigenetic changes. The results are discussed in relation to the plasticity of the development and differentiation of individual organs.
\end{abstract}

Keywords: Lycopersicon esculentum L.; Differentiation; Epigenetic variation; Somaclonal variation; Flow cytometry; DNA replication

*Corresponding author, Fax: (+31) 8370 15983; E-mail:m.j.m.smulders@cpro.agro.nl. 


\section{Introduction}

Endoreduplications are repeated cycles of DNA synthesis without intervening cell divisions, leading to endopolyploid cells [1,2]. In differentiated plant cells the phenomenon of endopolyploidy is the rule rather than the exception, and has been observed in almost all species studied $[2,3]$. During differentiation, cells of various ploidy levels occur in one and the same organ. This was termed polysomaty by Langlet in 1927 [4,5]. Within a species, the patterns of polysomaty are specific for the organ type and its developmental stage $[6,7,8]$, but can be influenced by environmental conditions during plant development $[9,10]$. The organ specificity of the patterns of polysomaty suggests a genetic regulation of this phenomenon, as an integral part of plant morphogenesis [10]. Many of the earlier data on polysomaty have been obtained using cytophotometry (microdensitometry) in Feulgen-stained preparations [3]. Using flow cytometry, it is now feasible to rapidly determine nuclear DNA contents of large populations of plant cells $[5,8,10]$, and therefore also to study the patterns of polysomaty in several individual tissues or organs.

The phenomenon of polysomaty is of importance for in vitro propagation, because polysomatic tissues, i.e. tissues of a diploid plant that contain large fractions $4 \mathrm{C}$ - and $8 \mathrm{C}$-cells (where $1 \mathrm{C}=$ the ploidy level of the germ line cells), may give rise to tetraploid or octaploid regenerant shoots [5,11] (Smulders and Rus-Kortekaas, unpublished material). In this way, the polysomatic nature of the original explant may explain some of the variation found in regenerants after certain kinds of in vitro propagation [5,6]. This variation was coined somaclonal variation by Larkin and Scowcroft [12]. De Klerk [13] defines somaclonal variation as genetic variation in plants regenerated from tissue culture, as opposed to epigenetic variation, which is not inherited. De Klerk [13] also indicates (i) that the two types of variation cannot be distinguished without sexual reproduction, and (ii) that the difference between these two types of variation is not an all or nothing phenomenon, as is clear for e.g. DNA methylation, which is transmitted through meiosis but is also reversible.
Somaclonal variation consists of a variety of genetic changes, ranging from mutations in one gene to chromosomal arrangements, aneuploidy and polyploidy. An increase in variation in quantitative characteristics such as length and yield was found in sugar cane, rice and wheat $[14,15]$. De Klerk et al. [16] showed that in Begonia the standard deviation of the average ratio between largest and smallest leaf vein length had changed after in vitro regeneration, but not the average ratio itself. Thus, the development of the leaves had become more variable. Since the Begonia cultivar used was completely sterile, it could not be established whether the variation had a genetic basis.

Tissue culture propagation might also cause genetic variation in the developmental program of endoreduplications in regenerants and their offspring, just as it can affect other developmental parameters. This paper is the first to determine whether such an effect of tissue culture propagation on the development of polysomaty can be measured. For this, first and second generation seedlings of regenerants of tomato (Lycopersicon esculentum $\mathrm{L}$.) were compared to control seedlings of the cultivar Moneymaker. Since both the average pattern of polysomaty and the variation around the mean pattern, i.e. the variability of the process, might be affected, populations of progeny seedlings were studied. The individual seedlings were grown under similar conditions to the same developmental stage, and polysomaty was analyzed by flow cytometry of four different organs: the leaf, the cotyledon, the transition zone between hypocotyl and root, and the secondary root.

\section{Materials and methods}

\subsection{Plant material}

Seeds from Lycopersicon esculentum cv. Moneymaker were harvested from one parental plant grown in the greenhouse and self-pollinated in the summer of 1991. First-generation regenerant seeds (R2) were harvested in the summer of 1988 from selfed individual plants ( $R 1)$ regenerated from cv. Moneymaker seedling parts by tissue culture [17]. The regenerant lines used here were obtained from Dr R. van den Bulk (CPRO-DLO, Wageningen, The Netherlands), and they were selected so as to contain both normal plants and 
plants carrying a mutation induced by the tissue culture propagation, e.g. an anthocyanin mutation. The plants developed normally. Secondgeneration seeds (R3) were obtained as follows: after germination in vitro and flow cytometric analysis of one cotyledon (see below), selected first-generation seedling plants were transferred to soil, grown in the greenhouse in the fall of 1992 , and allowed to self-pollinate and set fruit.

For flow cytometric analyses, all seedlings were grown aseptically for 18-33 days after start of imbibition on MS-medium (Duchefa, Amsterdam, The Netherlands) supplemented with $2 \%$ sucrose and $0.65 \%$ agar (BBL) in $720-\mathrm{ml}$ glass jars in a growth room at $20^{\circ} \mathrm{C}$ and $16 \mathrm{~h} /$ day light (Philips fluorescent TL type 50-W 84HF). Of each plant, up to four organs were analyzed by flow cytometry: leaf (the entire first developing leaf, including petiole), cotyledon (one whole cotyledon including petiole), transition zone (the basal part of the hypocotyl, adjacent to the root) and root (secondary roots).

\subsection{Flow cytometry}

The separate parts of each plant were measured by flow cytometry according to Gilissen et al. [8]. In brief, the organ parts were chopped individually with a sharp razor blade in $2 \mathrm{ml}$ nucleus isolation buffer (containing $1 \mathrm{mg} / 1$ 4,6-diamino-2-phenylindole (DAPI) for fluorescent DNA staining). After chopping, the samples were passed through a $55 \mu \mathrm{m}$ nylon filter (Nybolt). The DNA content of the isolated nuclei in the sample was measured using a Partec PAS-II flow cytometer equipped with a HBO-100 mercury lamp, a dichroic mirror TK420, and a long-pass filter GG435. The data were plotted on a semi-logarithmic scale, so that the histogram peaks from $2 \mathrm{C}$ to $32 \mathrm{C}$ were evenly distributed along the abscissa. For calibration, the $2 \mathrm{C}$-peak of nuclei of young leaves from in vitro grown tomato seedlings was used. At least 5000 nuclei were measured per sample.

\subsection{X-Ray analysis}

The internal morphology of second-generation seeds was studied by $\mathrm{X}$-ray photography of dry seeds according to Van der Burg et al. [18].

\subsection{Analysis of results}

The number of nuclei that was present in the peaks of the histogram was analyzed measuring peak height, which is linearly related to the number of nuclei. The data were calculated as percentage of the total amount of nuclei in all peaks of the histogram. Differences in the standard deviations were determined using a Student's $t$-test. Although the data consisted of percentages, there was no or insignificant deviation from a normal distribution in 28 out of 32 cases.

\section{Results}

\subsection{Natural variation in polysomaty patterns of tomato seedlings}

The four organs to be studied, namely leaf, cotyledon, transition zone and root, had strikingly different average patterns of polysomaty, when seedlings were germinated and grown in vitro for 2.5-4.5 weeks (Table 1) [10]. During these two weeks, the average polysomaty patterns stayed constant (not shown). Although the seedlings continued to develop new leaves and internodes during this period, the sizes of the organs already formed remained constant.

Table 1

Comparison of variation in polysomaty patterns in various organs of the seedlings of tomato cv. Moneymaker.

\begin{tabular}{lllll}
\hline C-level & \multicolumn{4}{l}{ Mean percentage of nuclei with various C-levels (range of $95 \%$ of the measurements) } \\
\cline { 2 - 5 } & Leaf & Cotyledon & Transition zone & Secondary root \\
\hline$N$ & 42 & 56 & 33 & 31 \\
$2 C$ & & & & \\
$4 C$ & $82(71-90)$ & $52(39-64)$ & $29(19-43)$ & $23(19-31)$ \\
$8 C$ & $16(10-25)$ & $39(30-47)$ & $42(30-50)$ & $66(59-75)$ \\
$16 C$ & $2(0-7)$ & $9(3-14)$ & $22(3-34)$ & $11(3-16)$ \\
& $0(0-0)$ & $1(0-4)$ & $7(0-15)$ & $0(0-0)$ \\
\hline
\end{tabular}



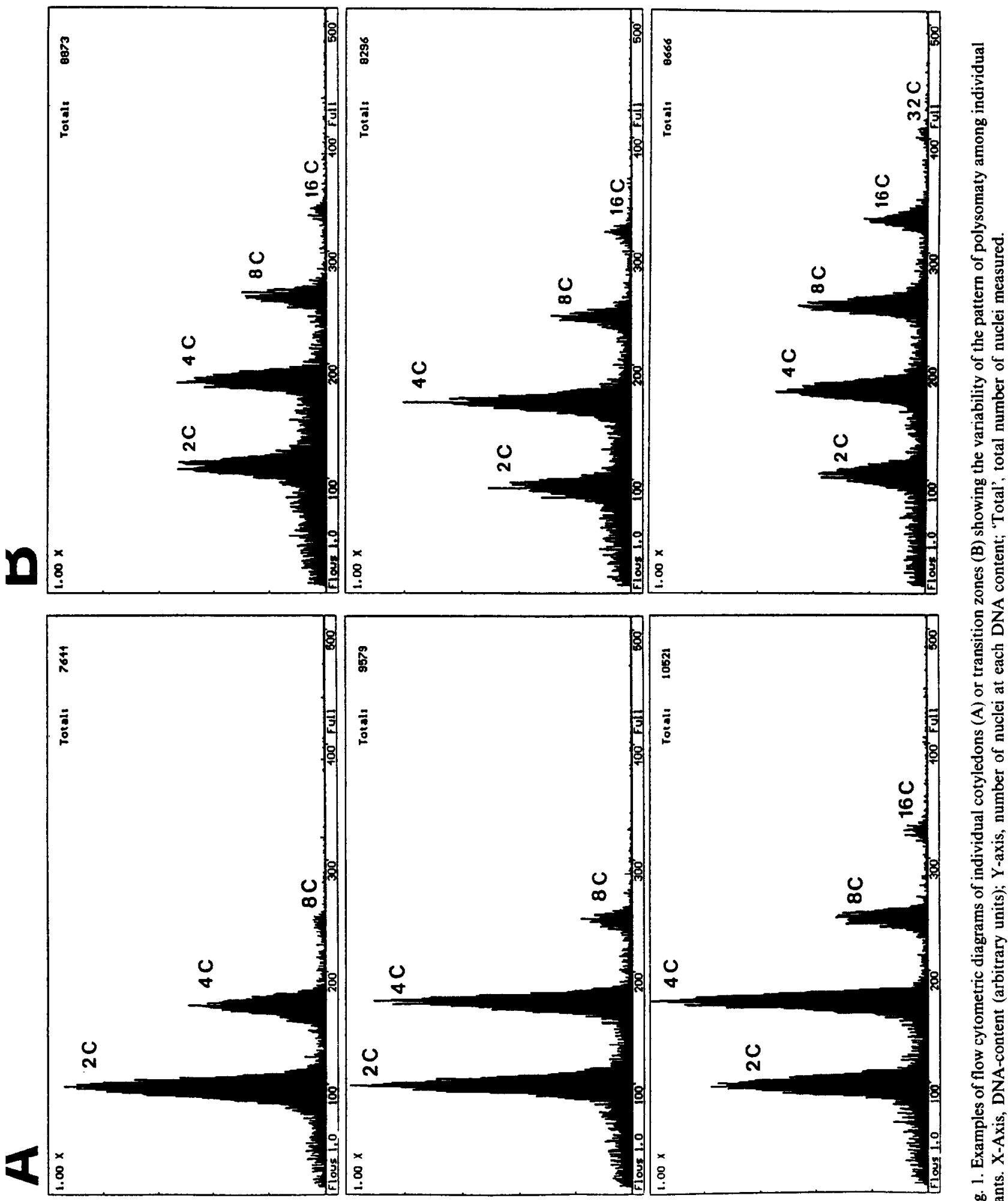
If we are to determine differences in polysomaty patterns between control and regenerant seedlings, it is important to quantify not only the average patterns of polysomaty, but also the degree of variation around the mean. The natural degree of variation in frequencies of nuclei at different C-levels was determined in the four organs of up to 56 seedling plants by flow cytometric analysis. In Table 1 , the degree of variation around the mean is expressed as the $95 \%$ confidence interval, i.e. the upper and lower limits for $95 \%$ of the measured values. It is clear that the variation around the mean differed among the organs tested. Unexpectedly, high levels of variation were found in the cotyledons and the transition zone. In these organs, highly diverse patterns of polysomaty were observed among individual plants, in such a way that nuclei of several C-levels could form the largest class of nuclei (examples are shown in Fig. 1).

Insight into the nature of this variation may be gained from an analysis of the data on individual seedlings. First, it was determined whether there was a relationship among the frequencies of nuclei in any given organ, or among the various organs. For this, the data on the frequencies of $4 \mathrm{C}-, 8 \mathrm{C}$-, and 16C-nuclei in individual organs were plotted

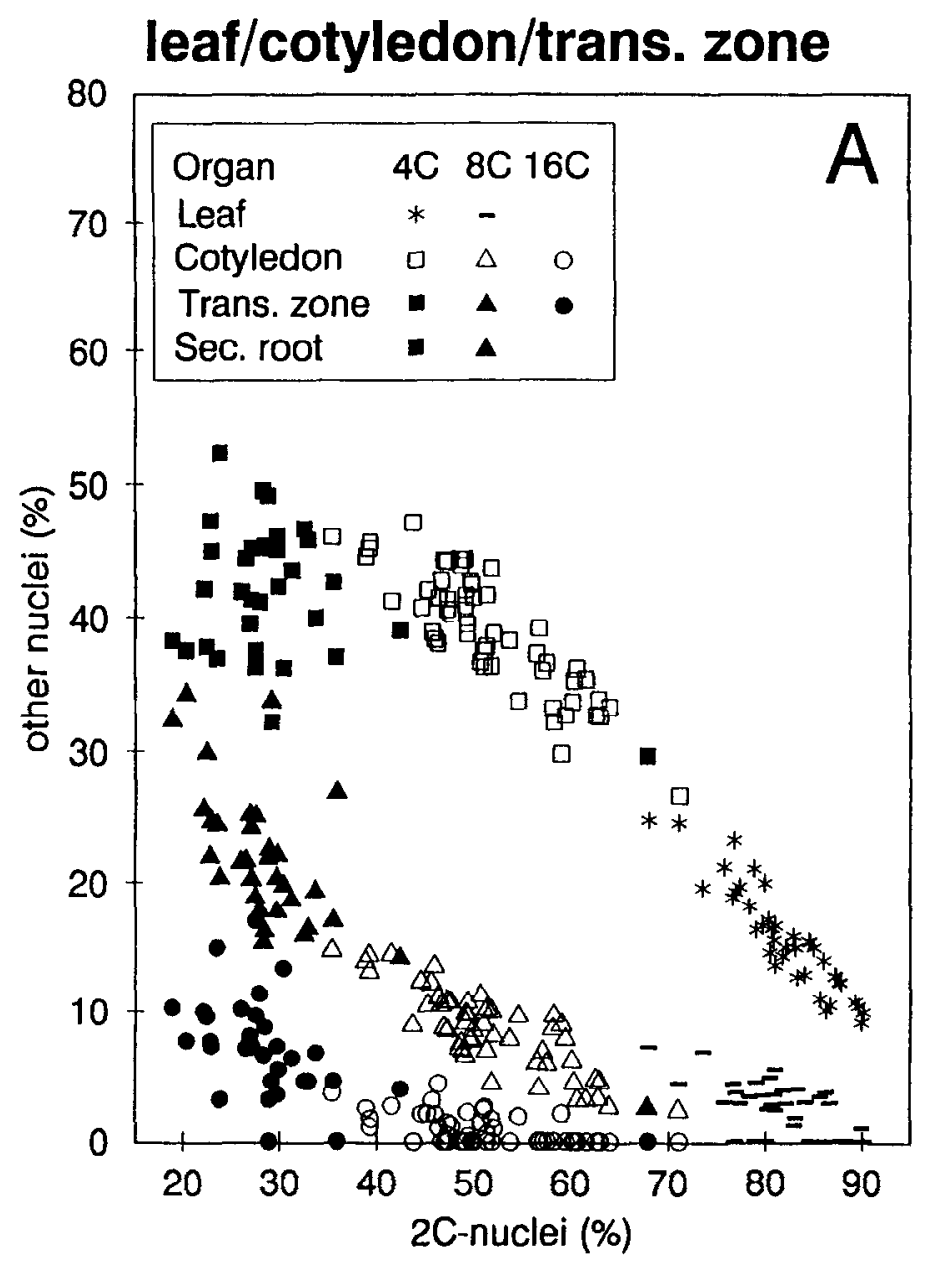

\section{secondary root}

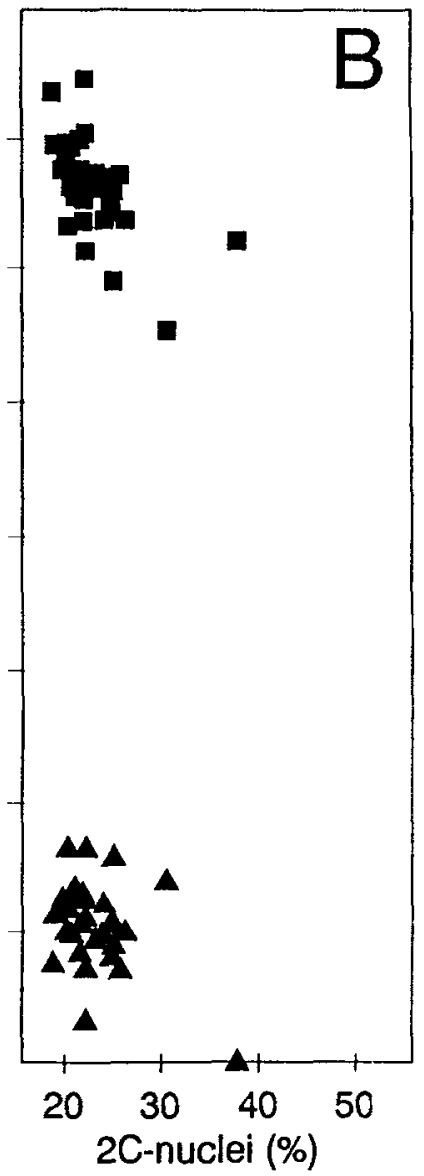

Fig. 2. Correlation between the percentages of $2 \mathrm{C}$-nuclei (X-axis) and the percentages of $4 \mathrm{C}$-, $8 \mathrm{C}$ - and $16 \mathrm{C}$-nuclei (Y-axis) by flow cytometric measurements of individual leaves, cotyledons and transition zones (A) and secondary roots (B) of $31-56$ tomato cv. Moneymaker seedlings grown in vitro for 18-33 days. 
against the frequencies of $2 \mathrm{C}$-nuclei in the same organs. In Fig. 2A, the fractions of nuclei at higher C-levels increased gradually as 2 C-levels diminish. The increase appears to fit in one continuous pattern, irrespective of the type of organ (leaf, cotyledon or transition zone) the data are taken from. Only the data from transition zones showed an increased level of random variation. The secondary roots have a cluster of values around a mean (Fig. 2B), and do not resemble the other organs tested. These results imply that the relationship between the C-values in individual organs is characterized fairly well by the frequency of $2 \mathrm{C}$-cells only. For instance, from Fig. $2 \mathrm{~A}$ it can be seen that when an individual cotyledon contains $50 \% 2 \mathrm{C}$ nuclei, it will also contain $38-46 \% 4 \mathrm{C}$ nuclei, and approximately 5-12\% 8C-nuclei. However, no cotyledon with 50\% 2C-nuclei contains 30\% 4C-nuclei and $20 \% 8 \mathrm{C}$-nuclei. This was used for the analyses of the experiments described below.

Next, it was determined whether there was a relationship among the frequencies of nuclei in

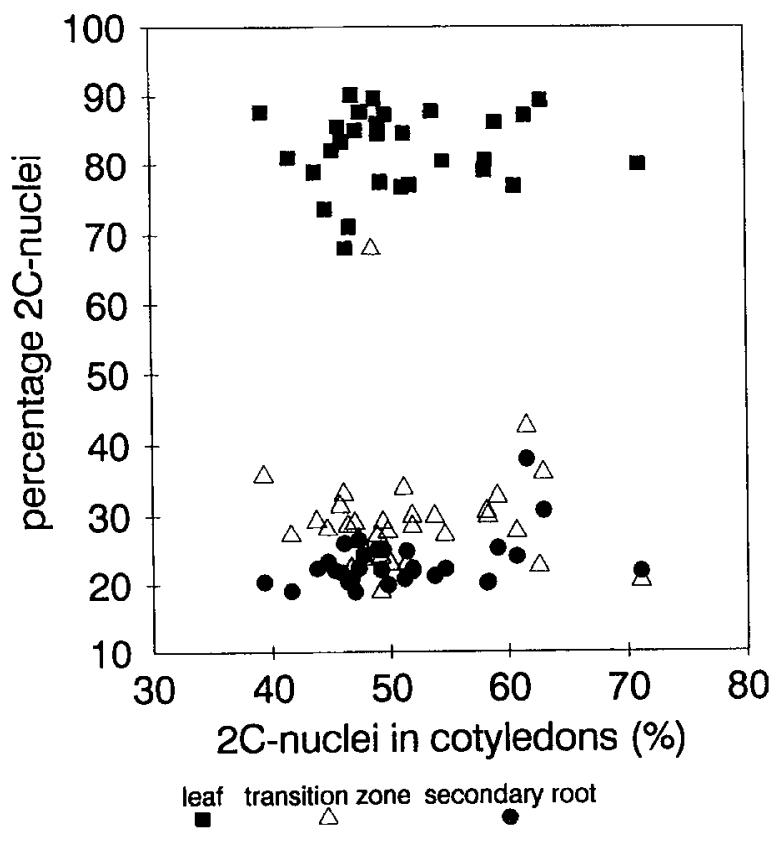

Fig. 3. Correlation between the percentages of $2 \mathrm{C}$-nuclei in the cotyledon (X-axis) and the percentages of $2 \mathrm{C}$-nuclei in the leaf, transition zone and secondary root $(\mathrm{Y}$-axis) of individual seedlings. A total of 31-56 seedlings grown in vitro for 18-33 days, were analyzed by flow cytometry for nuclear DNA content. various organs of one seedling. For this, the data on the frequencies of $2 \mathrm{C}$-cells in the cotyledons were plotted against those in the other organs of the same individual seedlings. As is clear from Fig. 3 , there is no relationship among the $2 \mathrm{C}$-values in different organs of one plant. This indicates that, even though the endoreduplications in leaf, cotyledon and transition zone fit a continuous pattern, the extent of the process is not correlated among the three organs of any individual plant.

3.2. Deviations in patterns of polysomaty in seedlings of regenerated plants

The effect of a tissue-culture regeneration process on the development of polysomaty patterns during seedling development was estimated first by comparing the patterns in four organs (leaf, cotyledon, transition zone and root) of one or a few seedlings from each of 30 different plants that had been regenerated from tissue culture, with those of the Moneymaker seedlings described above. Between 54 and 92 plants were tested for each organ.

All $\mathrm{C}$-values in the four organs of one plant were compared with the $95 \%$-confidence intervals of the percentage of nuclei at different $\mathrm{C}$-levels in the control Moneymaker population described in Table 1. For the root tissue, $5.1 \%$ of the measurements were outside this interval. A slightly elevated frequency was found for transition zone and leaf tissue: $8.0 \%$ and $9.4 \%$, respectively. The highest frequency was observed in the cotyledons: $18.9 \%$ of all percentage nuclei measured were outside the $95 \%$-confidence limits for control organs. Apparently, these four organs differed significantly in the increase of variation caused by tissue culture.

In a further screening, populations of 10-20 first-generation seedlings were analyzed from each of 16 direct regenerants. Among leaf, transition zone and root, organs that had shown no or a slight increase of variation, only one case (regenerant 85) was found in which the population had shifted to lower levels of $2 \mathrm{C}$-nuclei (all leaves contained between 68 and $74 \% 2 \mathrm{C}$-nuclei) and higher levels of $8 \mathrm{C}$-nuclei (all leaves had between 5 and $8 \% 8 \mathrm{C}$-nuclei). In contrast, aberrations were found in cotyledons of seven seedling lines, including populations with a frequency distribution 
shifted to higher or lower 2C-percentages, populations with a skewed frequency distribution, and lines segregating into two populations. Fig. 4A shows the frequency distributions of $2 \mathrm{C}$-values measured in the cotyledons of four of these lines.

The inheritance of the deviating patterns was studied in the progeny of some selected seedlings from each of the deviating lines. In total, cotyledons of 8-16 seedlings of each of 26 firstgeneration plants were measured. Some representative results are presented in Fig. 4B. The patterns of deviation of the first-generation populations were not transmitted to the second-generation populations, since no relation was found between the $2 \mathrm{C}$-value of the first-generation plant and the distribution of the $2 \mathrm{C}$-values in its second-
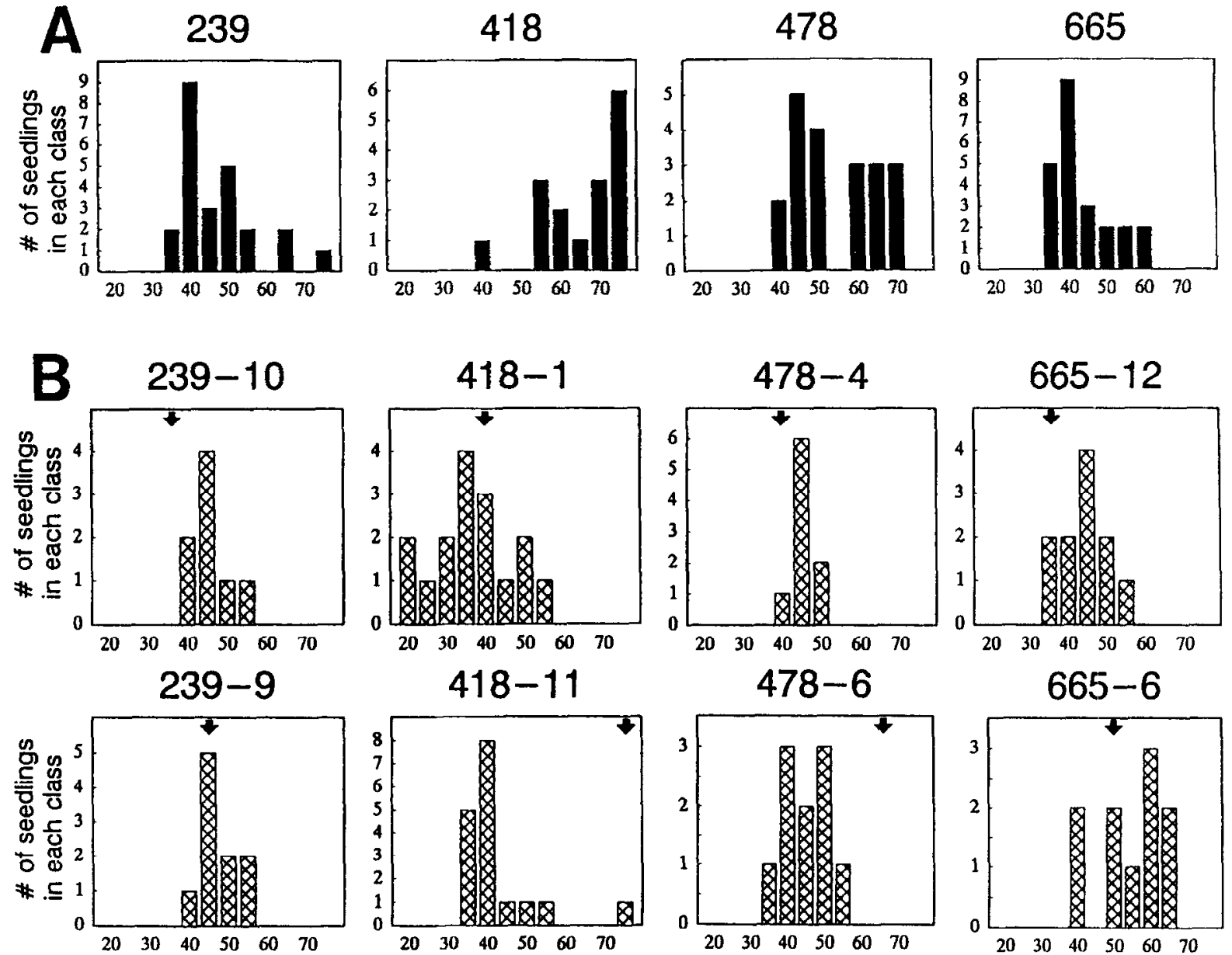

percentage $2 \mathrm{C}$-nuclei in an individual cotyledon (classes of $5 \%$ wide)

Fig. 4. Frequency distributions of the percentages of $2 \mathrm{C}$-nuclei in cotyledons of either first-generation seedlings from regenerant plants (A) or second-generation seedlings from selected first-generation plants (B). X-Axes, classes of values for the percentage of $2 \mathrm{C}$-nuclei in an individual cotyledon; classes are $5 \%$ wide, upper value is indicated (e.g. ' 30 ' is the class from $25.01 \%$ to $30.00 \% 2 \mathrm{C}$-nuclei). YAxes, number of seedlings with 2C-values in each class. First-generation lines 418, 478 and 665 deviated significantly from the control Moneymaker population in the mean percentage of $2 \mathrm{C}$-nuclei, line 239 showed a skewed distribution and line 478 appeared to segregate (A). The arrow in the frequency distributions of second-generation seedlings $(B)$ indicates the $2 \mathrm{C}$-percentage class of the firstgeneration parent plant. 
generation progeny. In fact, all second-generation populations were similar to each other, with only two exceptions, at low significance $(0.10<P<$ 0.05 ), for the average $2 C$-value of the progeny of line 418 seedling 1 and line 665 seedling 6 . No aberrations were found in the leaves of line 85 second-generation seedlings (not shown).

These results suggest that the aberrations found in the first-generation seedlings were not caused by genetic changes. Therefore, if the first- and second-generation populations are considered genetically homogeneous populations, mean values and variation coefficients can be calculated for the pooled populations. The average frequen- cies of nuclei at the different $\mathrm{C}$-levels were not significantly different between the pooled population and the control seedling population (results not shown). However, the standard deviation in the first-generation seedlings' organs was significantly higher than in the control Moneymaker seedlings for all organs except the transition zone (Table 2). For the cotyledons, the data allow the comparison of the first-generation selected parent population with their second-generation progeny: in the latter plants, the standard deviations were significantly smaller than in their first-generation parents, and comparable to the control Moneymaker plants.

Table 2

Comparison of standard deviations in control and regenerant tomato seedlings

\begin{tabular}{|c|c|c|c|c|}
\hline \multirow[t]{2}{*}{ C-level } & \multicolumn{4}{|l|}{ Plant material } \\
\hline & $\begin{array}{l}\text { Moneymaker } \\
\text { seedling }\end{array}$ & $\begin{array}{l}\text { First-generation seedl- } \\
\text { ings of direct } \\
\text { regenerants }\end{array}$ & $\begin{array}{l}\text { First-generation parents } \\
\text { of second-generation } \\
\text { seedlings }\end{array}$ & $\begin{array}{l}\text { Second-generation } \\
\text { seedlings }\end{array}$ \\
\hline \multicolumn{5}{|l|}{ Leaf } \\
\hline$N$ & 42 & 121 & & \\
\hline $2 \mathrm{C}$ & 5.1 & $6.4^{*}$ & & \\
\hline $4 C$ & 3.9 & $5.0^{*}$ & & \\
\hline $8 \mathrm{C}$ & 2.1 & 2.1 & & \\
\hline \multicolumn{5}{|c|}{ Cotyledon } \\
\hline$N$ & 56 & 277 & 26 & 289 \\
\hline $2 C$ & 7.1 & $10.3^{* * *}$ & $11.7 * * *$ & 8.2 \\
\hline $4 \mathrm{C}$ & 4.5 & $6.0^{* *}$ & 5.1 & 4.4 \\
\hline $8 C$ & 3.2 & $4.3^{* *}$ & $6.3^{* * *}$ & $4.0^{*}$ \\
\hline \multicolumn{5}{|c|}{ Transition zone } \\
\hline$N$ & 33 & 114 & & \\
\hline $2 \mathrm{C}$ & 8.3 & 8.0 & & \\
\hline $4 \mathrm{C}$ & 5.0 & 5.2 & & \\
\hline $8 C$ & 6.1 & 5.0 & & \\
\hline $16 C$ & 3.9 & 3.6 & & \\
\hline \multicolumn{5}{|c|}{ Secondary roots } \\
\hline$N$ & 31 & 92 & & \\
\hline $2 \mathrm{C}$ & 3.7 & 3.5 & & \\
\hline $4 \mathrm{C}$ & 3.8 & $6.3^{* * *}$ & & \\
\hline $8 C$ & 3.4 & $6.1^{* * *}$ & & \\
\hline
\end{tabular}

*Significantly different from the S.D. of Moneymaker seedlings at $P<0.05$.

- Significantly different from the S.D. of Moneymaker seedlings at $P<0.01$.

***Significantly different from the S.D. of Moneymaker seedlings at $P<0.001$. 


\subsection{Sources of variation}

In a search for physiological mechanisms that might be potential sources of variation in these regenerant seedlings, embryo morphology prior to germination was studied using $\mathrm{X}$-ray photography of 100 first- and second-generation seedlings prior to imbibition and germination, and compared to the patterns of polysomaty in the cotyledons after germination. The first-generation seeds, that showed aberrations in polysomaty patterns in the cotyledons after germination, were found to have a normal morphology. In contrast, the secondgeneration seeds, which had normal polysomaty patterns after germination, were found to have depleted endosperm, which is presumably related to the fact that they were harvested from tomatoes that had ripened in winter (results not shown). Apparently, the endosperm depletion did not influence the endoreduplication processes in the cotyledon after germination.

Fig. 5 shows data on the relationship between the percentage of nuclei with the 2C-DNA level and the length of the cotyledon in secondgeneration seedlings. These and other results (not shown) indicated that the size of the cotyledon (length of petiole, length of blade, or total length),

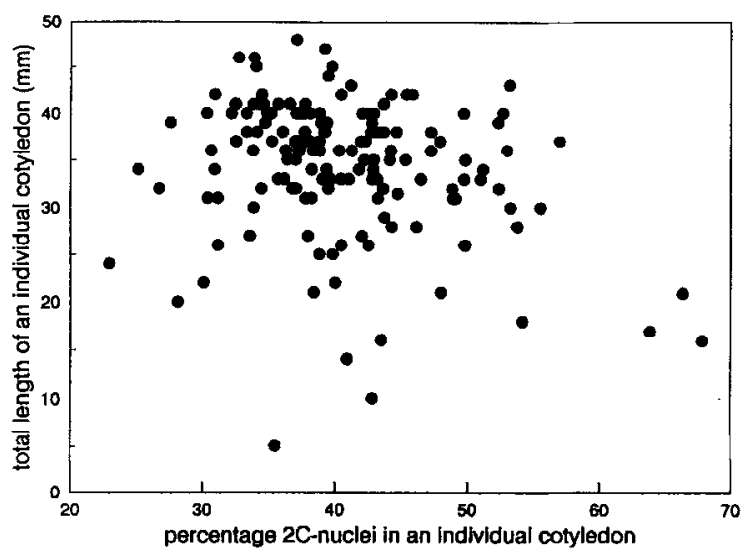

Fig. 5. Correlation between the pattern of polysomaty and the size of individual cotyledons. Percentage $2 \mathrm{C}$-nuclei in a cotyledon (X-axis) plotted against the length of the same cotyledon (petiole plus lamina) at the time of measurement (Y-axis). A total of 152 second-generation seedlings grown in vitro for 25-28 days were individually analyzed. transition zone, or leaf did not correlate with the particular pattern of polysomaty in that organ.

\section{Discussion}

'Organ-specific' patterns of polysomaty were found to vary considerably among seedlings of one tomato plant. The largest variation was observed in cotyledons and the transition zone from hypocotyl to root (Fig. 1). In all organs, the standard deviation around the mean percentage of $2 \mathrm{C}$ nuclei was between $3.7 \%$ and $8.3 \%$. In most studies, the occurrence of 'typical' organ-specific patterns has been reported. As an exception, Brown et al. [19] presented five flow cytometry patterns of each of several Arabidopsis organs studied, from which we calculated a standard deviation for $2 \mathrm{C}$ levels ranging from $3 \%$ (leaf 1 ) to $14 \%$ (internode 4), with $8-9 \%$ as the most frequent value. These values are comparable to those obtained in the present study.

The variation found in the patterns of polysomaty was not random. When plotted against the $2 \mathrm{C}$-values (Fig. 2), the $4 \mathrm{C}$-values in the leaf, and the $4 \mathrm{C}$ - and $8 \mathrm{C}$-values in the cotyledon fitted well forming a continuous pattern. This may be interpreted as one process of endoreduplication occurring in all plants, but with the rate of progression of this process varying among individual plants. This continuity is also clear in the observation that some individual leaves with a relatively high level of polysomaty (low percentage of $2 \mathrm{C}$-nuclei) showed a pattern of polysomaty identical to that of cotyledons with a relatively low level of polysomaty (high percentage of $2 \mathrm{C}$-nuclei). Similarly, samples of cotyledons that were characterized by a low frequency of $2 \mathrm{C}$-nuclei, were indistinguishable from some transition zone samples.

These results seem to represent, at first sight, a series of individual cotyledons measured during development. However, the different patterns were gathered from seedlings sampled randomly over the period from 18 to 33 days after the start of imbibition, and there was no relationship between length and width of a particular organ and the endoreduplication pattern found in that organ (Fig. 5). Also, the number of endocycles in an individual cotyledon was not related to the number of cycles 
in the transition zone or the leaf of the same plant (Fig. 3). This suggests that the process of endoreduplication progressed separately in each organ. Remarkably, partial depletion of the endosperm in the seeds before germination, as visualized by X-ray photography, did not affect the process of endoreduplication in the cotyledons after germination.

In many species the amount of nuclear DNA appears to be correlated with the size of the cell $[3,11,20]$. Millerd and Whitfield [21] found a linear relationship between fresh weight and DNA content in endoreduplication-dependent cell expansion of Vicia cotyledons, and a non-linear, but tight, relationship between the length of the cotyledon and the DNA content. Similarly, in tobacco stem internodes, where tissue elongation is the result of cell expansion, a clear correlation was found between cell size and DNA content (Gilissen et al., unpublished material). If this relation also holds in tomato, then cotyledons with the same size but different patterns of polysomaty must be made up of various mixtures of populations of cells with several sizes and matching ploidy levels.

The regulation of the endoreduplications, the organ-specificity of the polysomaty patterns, as well as the effect of growth conditions of the plant on polysomaty [10], should be explained in this context. The level of polysomaty, as well as the size of the cell, are closely linked to differentiation $[10,22]$ (Gilissen et al., unpublished material). Assuming that the regulation of polysomaty takes place at the cellular level, the tissue-specificity of the patterns must be the result of the specific amounts and sizes of cells that make up the organ. These cells, or at least most of them, may endoreduplicate according to the same basic pattern. Then, variation during the development of any organ, e.g. environmental stress, could lead to changes in the exact number and sizes of the cells among individual seedlings, and thus to variation in the actual pattern of polysomaty, but the patterns would still fit a continuous curve (Fig. 2). Since most organs develop one after the other, the varying influences from the environment and from other parts of the plant may be different for each organ. Therefore, the actual deviation from the 'mean' pattern may be unlinked to that in other organs of the same plant.

A consistent increase in the variation in polysomaty patterns was found in seedlings of regenerants derived from tissue culture (Table 2). In these seedlings, the S.D.s were significantly larger, ranging from $4.5 \%$ to $11.8 \%$ for $2 \mathrm{C}$-values. Some of the regenerants produced first-generation seedling populations displaying aberrations in the cotyledons. This could be interpreted as a more variable development of the cotyledon. An increase in the standard deviation of certain parameters after tissue culture was also found by De Klerk et al. [16] for leaf morphology in Begonia. However, the fact that the second-generation progeny did not show any of the deviations of the first-generation seedlings, suggests that the aberrations had no genetic basis, and, therefore, should not be called somaclonal variation. The occurrence of changes in the first-generation plants could be due to physiological or epigenetic changes. In the case of an epigenetic change, seed DNA methylation could be a possible mechanism to explain the combination of high frequency aberrations and labile inheritance. If so, the changes in DNA methylation can be expected to follow the pattern obtained here for polysomaty patterns: frequent changes in direct regenerants from tissue culture and their seedlings, but not in the next generation.

In a number of transition zone samples, a different kind of variation in polysomaty data was found. The variation was random, i.e. a loosened relationship between nuclei of different $\mathrm{C}$-levels. This may indicate the occurrence of processes such as polyploid mitoses [3]. It may also indicate that large numbers of cells in one or more tissues proceeded with endoreduplications while cells in other tissue did not, resulting in a 'mixed' organ endoreduplication pattern. In this regard, it may be important that the transition zone is the oldest organ sampled. It also must develop continually to be able to fulfill its functions in a growing plant. Therefore, it may have the highest degree of differentiation of the organs tested, especially under the in vitro growth conditions used. In roots, yet another process was visible: the polysomaty data of individual plants were scattered around one 
value instead of along a line. This suggests that the $4 \mathrm{C}$-level is a strictly regulated 'optimum' stage for root cells, or at least for the major part of the root cells.

In conclusion, the data in this paper indicate that, despite extensive variation among individual organs, endoreduplications proceed along a certain pattern, at least in young leaf and cotyledon tissue. The next step will be a quantification of the relationships between the fractions of cells at the different C-levels into a mathematical model. However, this will only be meaningful when based on individual data from a larger number of different organs, and measured under several environmental conditions. Such data are currently being gathered.

\section{Acknowledgements}

We thank H. Elbers for skillfully performing the flow cytometric measurements, W. Aartse for taking X-ray pictures, Dr R.C. Jansen for statistical advice, and Dr R.J. Bino, Dr K. Sree Ramulu and Dr B. Vosman for critical reading of the manuscript.

\section{References}

[1] W. Nagl, DNA endoreduplication and polyteny understood as evolutionary strategies. Nature, 261 (1976) 614-615

[2] W. Nagl, Nuclear organization. Annu. Rev. Plant Physiol., 27 (1976) 39-69.

[3] W. Nagl, Endopolyploidy and Polyteny in Differentiation and Evolution. North-Holland, Amsterdam, 1978.

[4] F. D'Amato, Polyploidy in the differentiation and function of tissues and cells in plants. Caryologia, 4 (1952) 311-358

[5] K. Sree Ramulu and P. Dijkhuis, Flow cytometric analysis of polysomaty and in vitro genetic instability in potato. Plant Cell Rep., 3 (1986) 234-237.

[6] K. Sree Ramulu, Genetic instability during plant regeneration in potato: origin and implications. Plant Physiol. (Life Sci. Adv.), 6 (1987) 211-218.

[7] E.J. De Rocher, K.R. Harkins, D.W. Galbraith and H.J. Bohnert, Developmentally regulated systemic endopolyploidy in succulents with small genomes. Science, 250 (1990) 99-101

[8] L.J.W. Gilissen, M.J. van Staveren, J. CreemersMolenaar and H.A. Verhoeven, Development of polysomaty in seedlings and plants of Cucumis sativus $\mathbf{L}$. Plant Sci., 91 (1993) 171-179.

[9] H.R. Owen, R.E. Veillieux, D. Levy and D.L. Ochs, Environmental, genotypic and ploidy effects on endopolyploidization within a genotype of Solanum phureja and its derivatives. Genome, 30 (1988) 506-510.

[10] M.J.M. Smulders, W. Rus-Kortekaas and L.J.W. Gilissen, Development of polysomaty during differentiation in diploid and tetraploid tomato (Lycopersicon esculentum L.) plants. Plant Sci., 97 (1994) 53-60.

[11] L.J.W. Gilissen, M.J. van Staveren, J.C. Hakkert, M.J.M. Smulders, H.A. Verhoeven and J. CreemersMolenaar, The competence of cells for cell division and regeneration in tobacco explants depends on cellular location, cell cycle phase and ploidy level. Plant Sci., 103 (1994) 81-9!

[12] P.J. Larkin and W.R. Scowcroft, Somaclonal variation - a novel source of variability from cell cultures for plant improvement. Theor. Appl. Genet., 60 (1981) 197-214.

[13] G.J. de Klerk, How to measure somaclonal variation? Acta Bot. Neerl., 39 (1990) 129-144.

[14] A. Karp and S.W.J. Bright, On the causes and origins of somaclonal variation. Oxford Sury. Plant Mol. Cell. Biol., 2 (1985) 199-234.

[15] A. Karp, On the current understanding of somaclonal variation. Oxford Surv. Plant Mol. Cell. Biol., 7 (1991) $1-58$.

[16] G.J. de Klerk, J. ter Brugge and H. Bournan, An assay to measure the extent of variation in micropropagated plants of Begonia $\times$ hiemalis. Acta Bot. Neerl., 39 (1990) $145-151$

[17] R.W. van den Bulk, H.J.M. Löffler, W.H. Lindhout and M. Koornneef, Somaclonal variation in tomato: effect of explant source and comparison with chemical mutagenesis. Theor. Appl. Genet., 80 (1990) 817-825.

[18] W.J. van der Burg, J.W. Aartse, R.A. van Zwol, H. Jalink and R.J. Bino, Predicting tomato seedling morphology by X-ray analysis of seeds. J. Am. Soc. Hort. Sci., 119 (1994) 258-263.

[19] S.C. Brown, F. de Kouchkovsky, D. Marie, Polysomaty in plants, in: B.F. Kimler, J.E. O'Conner, F. Sansonetty and S.C. Brown (Eds.), The Porto Workshop on Flow and Image Cytometry, IPATIMUP Series 1. Fundaçao Eng. Antonio Almeida, Porto, 1995 (in press).

[20] J.E. Melaragno, B. Mehrota and A.W. Coleman, Relationship between endopolyploidy and cell size in epidermal tissue of Arabidopsis. Plant Cell, 5 (1993) 1661-1668.

[21] A. Millerd and P.R. Whitfield, Deoxyribonucleic acid and ribonucleic acid synthesis during the cell expansion phase of cotyledon development in Vicia faba L. Plant Physiol., 51 (1973) 1005-1010.

[22] P.W. Barlow, The root cap, in: J.G. Torrey and D.T. Clarkson (Eds.), The Development and Function of Roots. Academic Press. New York. 1975, pp. 21-54. 